Neurosurg Focus 9 (1):Article 8, 2000, Click here to return to Table of Contents

\title{
Spontaneous spinal cerebrospinal fluid leaks: a review
}

\author{
WOUTER I. SCHIEVINK, M.D. \\ Cedars-Sinai Neurosurgical Institute, Los Angeles, and Department of Neurosurgery, University of \\ California, Irvine, California
}

\begin{abstract}
Spontaneous intracranial hypotension has become a well-recognized clinical entity, but it remains an uncommonly, and probably underdiagnosed, cause of headache; its estimated prevalence is only one in 50,000 individuals. The clinical spectrum of spontaneous intracranial hypotension is quite variable and includes headache, neck stiffness, cranial nerve dysfunction, radicular arm pain, and symptoms of diencephalic or hindbrain herniation. Leakage of the spinal cerebrospinal fluid (CSF) is the most common cause of spontaneous intracranial hypotension. A combination of an underlying weakness of the spinal meninges and a more or less trivial traumatic event is often found to cause this event in these patients. Typical magnetic resonance imaging findings include diffuse pachymeningeal enhancement, subdural fluid collections, and downward displacement of the brain, sometimes mimicking a Chiari I malformation. Opening pressure is often, but not always, low, and examination of CSF may reveal pleocytosis, an elevated protein count, and xanthochromia. The use of myelography computerized tomography scanning is the most reliable method for the accurate localization of the CSF leak. Most CSF leaks are found at the cervicothoracic junction or in the thoracic spine. The initial treatment of choice is a lumbar epidural blood patch, regardless of the location of the CSF leak. If the epidural blood patch fails, the blood patch procedure can be repeated at the lumbar level, or a blood patch can be directed at the exact site of the leak. Surgical repair of the CSF leak is safe and generally successful, although a distinct structural cause of the leak often is not found.
\end{abstract}

\section{KeY WordS - cerebrospinal fluid leak - Chiari malformation • headache • hypotension - intracranial pressure • Marfan syndrome}

When a person is in the upright position, intracranial pressure is negative. ${ }^{9}$ Intracranial hypotension is defined as an abnormally low intracranial pressure, and it is characterized by headaches that worsen when standing and improve when lying down. The occurrence of such posture-related headaches is well known to all physicians in individuals who have undergone lumbar puncture as well as to neurosurgeons, in particular, who observe these headaches in patients following craniospinal traumatic injury or CSF shunt placement. Although a spontaneous form of intracranial hypotension was described more than 60 years ago ${ }^{67}$ it has only been recently that this condition has become a well-recognized clinical entity. Spontaneous intracranial hypotension is also known as essential aliquorrhea, spontaneous hypoliquorrhea, and Schaltenbrand syndrome. Georg Schaltenbrand ${ }^{67}$ was the German physician who first described patients with spontaneously occurring low CSF pressures, but his role in the Third Reich $^{77}$ should preclude the eponym from being used.

In this review I discuss recent developments in our understanding of the causes and pathogenesis of spontane-

Abbreviations used in this paper: CSF = cerebrospinal fluid; $\mathrm{CT}=$ computerized tomography; $\mathrm{MR}=$ magnetic resonance. ous intracranial hypotension, its clinical spectrum, methods of diagnosis, and approaches to treatment.

\section{EPIDEMIOLOGICAL CHARACTERISTICS}

Spontaneous intracranial hypotension is an increasingly diagnosed cause of headaches, and more than half of documented cases have been reported during the last decade. ${ }^{4,8,15,21,29,30,36,38,40,49,54,62,63,68,70,81,84}$ In the past, spontaneous intracranial hypotension was probably underdiagnosed, and it is not likely that there has been an actual increase in its incidence, although that possibility cannot be excluded. Comprehensive epidemiological studies have not been reported, but the prevalence of spontaneous intracranial hypotension in Olmsted County, MN, in 1995 was estimated at approximately one in 50,000 individuals. ${ }^{71}$ Spontaneous intracranial hypotension affects women more frequently than men, and the onset of symptoms typically occurs in the fourth or fifth decade of life. , $^{4,16,22,30}$ $37,39,41,50,55,63,64,69,71,72,82,85$

\section{CAUSES AND PATHOGENESIS}

Spontaneous spinal CSF leaks are the most common 
TABLE 1

Precipitating events in 29 patients with spinal CSF leaks and intracranial hypotension

\begin{tabular}{lc}
\hline \hline \multicolumn{1}{c}{ Cause } & No. of Cases \\
\hline roller-coaster ride & 1 \\
white-water rafting & 1 \\
bumped into table during a brawl & 1 \\
jet-skiing & 1 \\
childbirth & 1 \\
weight lifting & 1 \\
playing volleyball & 1 \\
sexual intercourse & 1 \\
jogging & 1 \\
fall on buttocks while roller-blading & 1 \\
\hline
\end{tabular}

cause of spontaneous intracranial hypotension. ${ }^{70}$ Because these CSF leaks generally do not cause any other symptoms, they often remain undetected. Other causes of symptomatic spontaneous intracranial hypotension, such as spontaneous CSF rhinorrhea or otorrhea, diabetic coma, or uremia, are less common, and their diagnosis is usually straight forward because of the obvious associated symptomatology.

The exact cause of spontaneous spinal CSF leaks largely remains unknown, but an underlying weakness of the spinal meninges is generally suspected, ${ }^{69-73}$ and a more or less trivial traumatic event often precedes the onset of symptoms (Table 1). ${ }^{4,23,49,52,69}$ The structural dural weakness predisposes to the formation of fragile meningeal diverticula or simple dural rents that allow CSF to leak into the extradural space. There is good evidence to suggest that a generalized connective tissue disorder may play an important role in the development of spontaneous spinal CSF leaks and intracranial hypotension, as first reported in $1994 . .^{72}$ In approximately one fifth of patients with spontaneous CSF leaks and intracranial hypotension, subtle skeletal abnormalities are commonly observed such as those seen in Marfan syndrome-tall stature, joint hypermobility, and arachnodactyly - but no other stigmata of the syndrome are found in these patients (Fig. 1)..$^{70,72,73}$ In some of these patients an abnormality of fibrillin metabolism is expressed. ${ }^{75}$ Another associated finding, suggesting the presence of a generalized connective tissue disorder, is the occurrence of spontaneous retinal detachment at an early age in patients with spontaneous CSF leaks. ${ }^{70}$ Moreover, meningeal diverticula and spontaneous intracranial hypotension have been described in several well-characterized, generalized connective tissue disorders such as autosomal dominant polycystic kidney disease, ${ }^{75}$ Marfan syndrome, ${ }^{13,18,22}$ neurofibromatosis type $1,{ }^{17,42}$ and Lehman syndrome. ${ }^{37,58}$

In rare circumstances spontaneous spinal CSF leaks are caused by an extradural pathological entity, such as a bone spur that pierces the dura. ${ }^{16,83}$

In the past, some authors have speculated that spontaneous intracranial hypotension results from decreased CSF secretion or generalized CSF hyperabsorption. ${ }^{34,35,40,67,68}$ However, there are no data to support how these alternate mechanisms lead to a decrease in CSF pressure. Much remains to be learned about the pathophysiology of sponta-

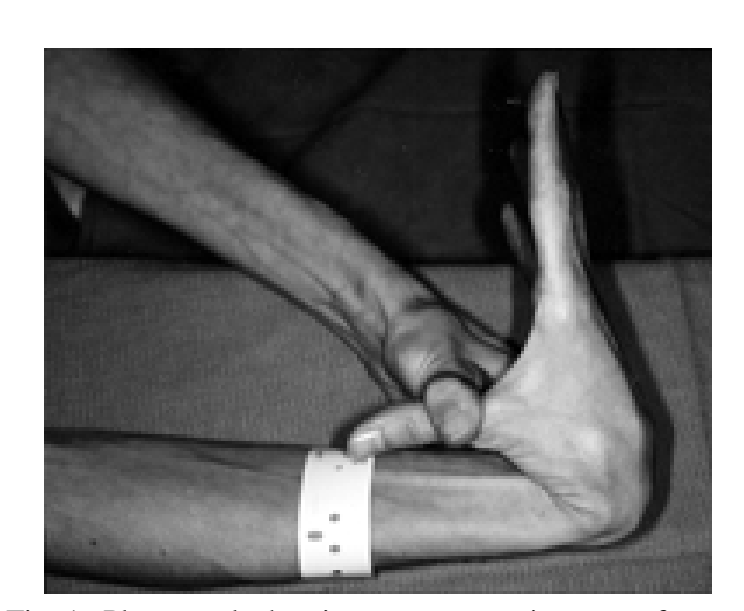

Fig. 1. Photograph showing a representative case of a generalized connective tissue disorder in spontaneous intracranial hypotension. Arachnodactyly and joint hypermobility were present in this 30-year-old woman with a spontaneous CSF leak at the thoracolumbar junction.

neous intracranial hypotension, and a decrease in CSF volume, rather than in CSF pressure, may be the final common pathway.

\section{CLINICAL PRESENTATION}

\section{Posture-Related Headache}

The clinical hallmark of intracranial hypotension is the presence of an orthostatic headache that, according to the criteria of the International Headache Society, ${ }^{27}$ should "occur or worsen less than 15 minutes after assuming the upright position, and disappear or improve less than 30 minutes after resuming the recumbent position." The onset of the individual's headache generally is gradual or subacute and often is first noted upon arising in the morning. However, in some patients the onset is acute ("thunderclap" headache), and such patients often will have undergone cranial CT scanning and cerebral angiography to rule out an aneurysmal subarachnoid hemorrhage. The severity of the headache varies widely, and many mild cases undoubtedly are never diagnosed. On the other hand, the headaches may become quite incapacitating, preventing the patient from engaging in any useful activity while in the upright position. Such patients will characteristically present in a recumbent position to their physicians' offices. The headache may be generalized or it may be localized to the frontal or (sub)occipital regions. The headache most likely is a direct result of the decrease in CSF volume and the downward displacement of the brain, which causes traction on pain-sensitive structures, particularly the intracranial dura that is supplied by the trigeminal, glossopharyngeal, and vagal nerves, as well as the upper cervical nerve roots..$^{19,33}$

Although all patients in all major series have presented with orthostatic headaches it is well known that this posture-related component often becomes less prominent or even disappears over time when the intracranial hypotension is left untreated and becomes chronic. ${ }^{49,70}$ Rarely, patients with spontaneous intracranial hypotension have 


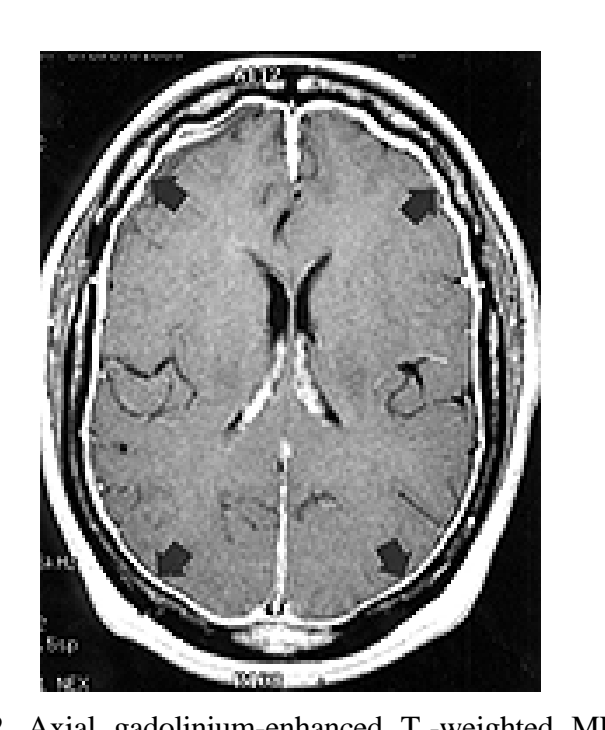

Fig. 2. Axial gadolinium-enhanced $\mathrm{T}_{1}$-weighted $\mathrm{MR}$ image demonstrating diffuse pachymeningeal enhancement (arrows) in a 54-year-old woman with a spontaneous CSF leak at the cervicothoracic junction. Note the absence of any leptomeningeal involvement.

been described in whom there is no posture-related component to their headaches from the onset. ${ }^{2,74}$

\section{Associated Symptoms}

A wide variety of symptoms may be associated with spontaneous intracranial hypotension. Nausea, vomiting, phonophobia, photophobia, and neck pain or stiffness are common symptoms and suggest meningeal irritation. Many of the other associated symptoms are believed to be directly related to the downward displacement of the brain, which is caused by the loss of CSF buoyancy. Horizontal diplopia, changes in hearing, and vertigo are present in at least one fourth of patients with spontaneous intracranial hypotension $2,4,6,8,20,29,49,63,70,84$ and may be caused by stretching of the abducens, cochlear, and vestibular nerves, respectively. A similar mechanism could also explain rarely seen manifestations of intracranial hypotension such as facial numbness or pain (trigeminal nerve), facial weakness or spasm (facial nerve), and dysgeusia (chord of tympanum or glossopharyngeal nerve). ${ }^{49,70}$ Transient visual obscurations or visual field defects also have been reported ${ }^{29}$ and may be attributed to the stretching of the optic apparatus over the pituitary fossa. Distortion of the pituitary stalk has been implicated as a cause of hyperprolactinemia and galactorrhea associated with spontaneous intracranial hypotension. ${ }^{85}$ Stretching of cervical nerve roots could even be implicated as a cause of the radicular arm pain occasionally found in patients with spontaneous intracranial hypotension. An alternative hypothesis to explain the disturbances of hearing or balance is that the abnormal change in CSF pressure is directly transmitted to that in the cochlea or labyrinth. Rarely, severe sagging of the brain may result in symptomatic diencephalic or hindbrain herniation. ${ }^{3,59,70}$ Other unusual manifestations may include parkinsonism and cerebellar ataxia. ${ }^{55}$ Local back pain may be present at the level of the spinal CSF leak, ${ }^{70}$ and structural abnormalities of

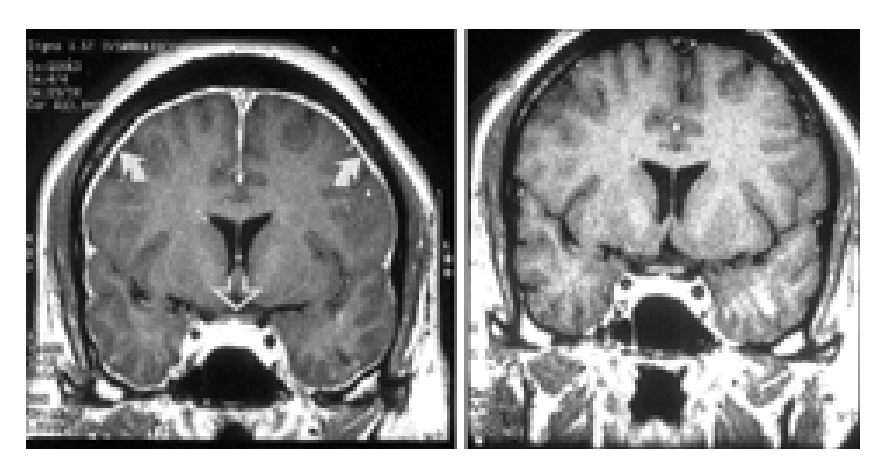

Fig. 3. Left: Coronal gadolinium-enhanced $\mathrm{T}_{1}$-weighted MR image revealing diffuse pachymeningeal enhancement (curved arrows) and bowing of the optic chiasm over the pituitary fossa (straight arrow) preoperatively (left). Right: Coronal image demonstrating resolution of the pachymeningeal enhancement and restoration of the crowding of the optic chiasm after surgical ligation of a leaking meningeal diverticulum of the left L-2 nerve root in a 41-year-old man.

the nerve root sleeves may cause radicular symptoms. Thus, although uncommon, certain symptoms may aid in localizing the level of the CSF leak.

\section{DIAGNOSIS}

\section{Cerebral MR Imaging}

Pachymeningeal Enhancement. Magnetic resonance imaging has revolutionized our understanding of intracranial hypotension and undoubtedly is one of the most important factors responsible for the ever-increasing number of patients in whom spontaneous intracranial hypotension can be diagnosed. Enhancement of the pachymeninges (that is, dura mater) following administration of gadolinium is the most characteristic neuroimaging feature of intracranial hypotension (Figs. 2 and 3).,2,21,25,28,29,45,49,56, $63,64,70,84$ This association was first reported in 1991 by Mokri and colleagues. ${ }^{47}$ The pachymeningeal enhancement is diffuse, thin, involves both supra- and infratentorial compartments, and may extend into the spinal canal. ${ }^{44}$ There has been debate as to the cause of the pachymeningeal enhancement observed on MR imaging. However, careful examination of meningeal biopsy samples consistently demonstrate a thin layer of fibroblasts in the socalled subdural zone as well as small thin-walled dilated blood vessels without evidence of inflammation. ${ }^{48}$ Meningeal fibrosis is seen only in patients with long-standing symptoms. ${ }^{48}$ These findings strongly suggest that dural venous dilation is the most likely explanation of the pachymeningeal enhancement in intracranial hypotension. Similarly, reactive hyperemia of the pituitary gland in patients with spontaneous intracranial hypotension may mimic a pituitary tumor. ${ }^{1,45,78}$

The presence of pachymeningeal enhancement on MR imaging has been considered to be the sine qua non of intracranial hypotension, and this neuroimaging finding has been believed to be so characteristic that the term "syndrome of orthostatic headache and diffuse pachymeningeal gadolinium enhancement" has been proposed. ${ }^{49}$ However, a small minority of patients never de- 


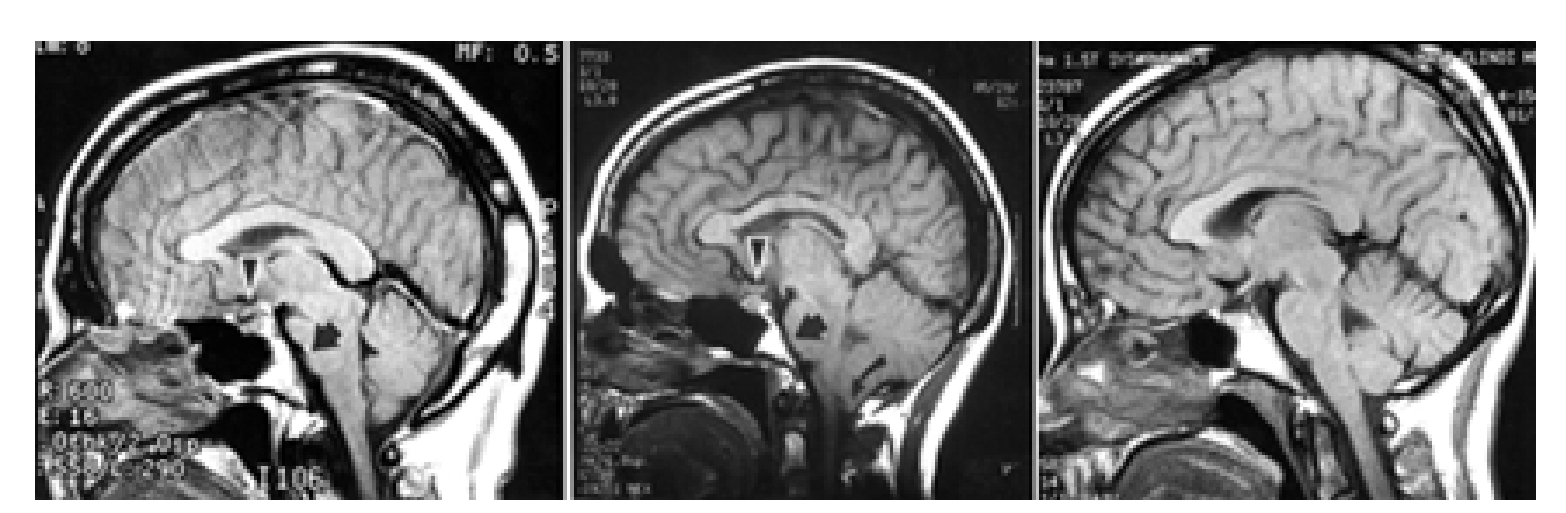

Fig. 4. Sagittal $\mathrm{T}_{1}$-weighted MR images representative of brain sagging and pseudo-Chiari malformation. Left: A $\mathrm{T}_{1}$-weighted image revealing inferior displacement of the optic chiasm (arrowhead) and severe flattening of the pons (straight arrow) in a 68-year-old man in whom a spontaneous CSF leak was demonstrated at the lumbosacral junction. Center: Image demonstrating inferior displacement of the optic chiasm (arrowhead), mild flattening of the pons (straight arrow), and cerebellar tonsillar herniation mimicking a Chiari I malformation (curved arrow) in a 40-year-old woman with a spontaneous CSF leak at the C-7 level. Right: For comparison, a sagittal $\mathrm{T}_{1}$-weighted image obtained in a healthy 38-year-old woman.

velop any meningeal enhancement as seen on MR imaging despite the presence of symptomatic intracranial hypotension. $46,53,76$

Brain Sagging and Pseudo-Chiari Malformation. Downward displacement of the brain, or brain sagging, is a very specific finding in cases of intracranial hypotension. It was first described in 1975 in a patient with spontaneous intracranial hypotension revealed on a pneumoencephalogram. ${ }^{7}$ Brain sagging can be identified by several features: effacement of the suprasellar cistern, bowing of the optic chiasm over the pituitary fossa, flattening of the pons against the clivus and obliteration of the prepontine cistern, and hindbrain herniation in which downward displacement of the cerebellar tonsils occurs. (Figs. 3-5)..$^{21,25}$, 29,32,45,56,63,70 Most of these changes are best visualized on the midline sagittal MR images. The displacement of the cerebellar tonsils into the spinal canal may be mistaken for a Chiari I malformation, and some patients with spontaneous intracranial hypotension have undergone decompressive posterior fossa surgery. ${ }^{70}$

Subdural Fluid Collections. Subdural hematomas and hygromas are commonly found in patients with spontaneous intracranial hypotension (Fig. 5). $2,8,9,21,22,25,29,36,49,51$, $56,62,63,65,66,70$ Most of these subdural fluid collections are bilateral, thin, and do not cause any appreciable mass effect. Occasionally, larger symptomatic subdural hematomas require surgical evacuation, and if the spinal CSF leak is left untreated, the recurrence rate of the subdural hematoma may be increased. ${ }^{51,65,66}$ It has been postulated that the subdural hematomas are caused by tearing of bridging veins resulting from the downward displacement of the brain. Alternatively, subdural hematomas may be caused by the rupture of the dilated thin-walled vessels in the subdural zone. The subdural hygromas may represent a compensatory increase of the subdural CSF spaces due to the downward displacement of the brain.

After successful treatment of the underlying CSF leak, improvement or resolution of the MR-documented abnormalities can be expected within several days or weeks (Fig. 3). Clinical improvement generally precedes that demonstrated on neuroimaging. In some patients, particularly those who have not received specific treatment for their CSF leak, considerable clinical improvement is shown over time whereas their MR-documented abnormalities persist. ${ }^{8,79}$ In most patients, the pachymeningeal enhancement is the first abnormality that resolves, whereas the brain sagging may linger for a considerably longer time or show only partial improvement. ${ }^{56,71}$

\section{Lumbar Puncture}

In current practice when the clinical history, physical examination, and imaging studies all are typical of spontaneous intracranial hypotension, additional evaluation may

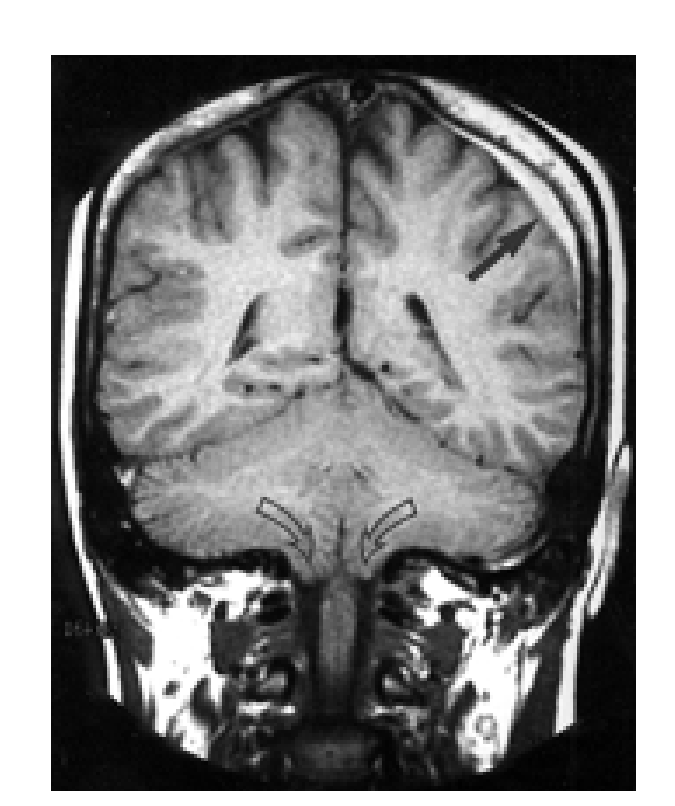

Fig. 5. Coronal $\mathrm{T}_{1}$-weighted MR image revealing a subacute left-sided subdural hematoma (straight arrow) and cerebellar tonsillar herniation (curved arrow) in a 42-year-old woman with a spontaneous CSF leak at the C-5 level. 


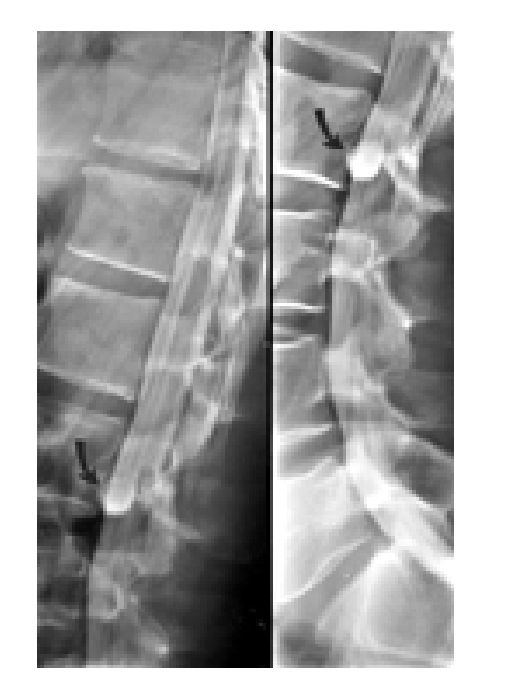

Fig. 6. Lateral thoracolumbar (left) and lumbar (right) myelogram demonstrating a meningeal diverticulum of the left L-2 nerve root (curved arrows) in a 41-year-old man with spontaneous hypotension.

not always be necessary, and the diagnosis can be made with confidence. Prior to the recognition of the characteristic cranial MR imaging findings, a lumbar puncture was the study of choice with which to confirm a diagnosis of intracranial hypotension. With the patient in the lateral recumbent position, normal opening pressure ranges from 65 to $195 \mathrm{~mm} \mathrm{H}_{2} \mathrm{O}(5-15 \mathrm{~mm} \mathrm{Hg})$ at the level of the lumbar spine. ${ }^{39}$ In patients with intracranial hypotension an opening pressure of less than $60 \mathrm{~mm} \mathrm{H}_{2} \mathrm{O}$ is characteristically demonstrated. ${ }^{62}$ Not infrequently, a "dry tap" is initially encountered, and CSF can only be obtained with a Valsalva maneuver, placing the patient in an upright position, or with aspiration by using a syringe. A sucking noise has also been described as the stylet is withdrawn and air enters the subarachnoid space, indicating subatmospheric pressure. ${ }^{4,38,67}$ It is now well recognized that in some patients with spontaneous spinal CSF leaks and in- tracranial hypotension who undergo serial lumbar puncture studies, variable readings of CSF pressure are demonstrated over time, including pressures well within the range of normal. ${ }^{49,70}$ This may indicate that the CSF leak is intermittent. Normal opening pressures are rarely consistently found in patients with well-documented spontaneous intracranial hypotension. ${ }^{49}$ Possibly these opening pressures are subnormal for these patients and their normal CSF pressure is at a higher range. Alternatively, normal, fully compensated CSF pressures may be found in these patients despite reduced CSF volumes.

Examination of a CSF sample often demonstrates abnormal findings. ${ }^{49,62}$ An elevated protein content $(>45$ $\mathrm{mg} / \mathrm{dl}$ ) is the most common abnormality and is present in more than three fourths of patients with intracranial hypotension. The increase usually is mild but may reach 1000 $\mathrm{mg} / \mathrm{dl}$. Pleocytosis ( $>$ five white cells $/ \mathrm{mm}^{3}$ ) is found in approximately half of patients. The pleocytosis is primarily lymphocytic and may exceed 200 white cells per $\mathrm{mm} .{ }^{77}$ Xanthochromia also has been reported. All these CSF abnormalities may be explained by a combination of increased permeability of the dilated meningeal blood vessels and a decrease of CSF flow in the lumbar subarachnoid space.

The fear of cerebral herniation or aggravating symptoms by performing a lumbar puncture is entirely theoretical and has never been documented in patients with spontaneous intracranial hypotension. Not only is the dural hole caused by a lumbar puncture relatively small but the CSF pressure is already low.

\section{Computerized Tomography Myelography}

Myelography with water-soluble contrast followed by CT scanning is the study of choice to confirm a diagnosis of spontaneous spinal CSF leak and accurately define its location (Figs. 6 and 7). ${ }^{70,71}$ Ideally, myelography should be performed in conjunction with the initial lumbar puncture. The use of CT myelography will demonstrate the presence of extrathecal contrast or of structural abnormalities responsible for the CSF leak, such as meningeal

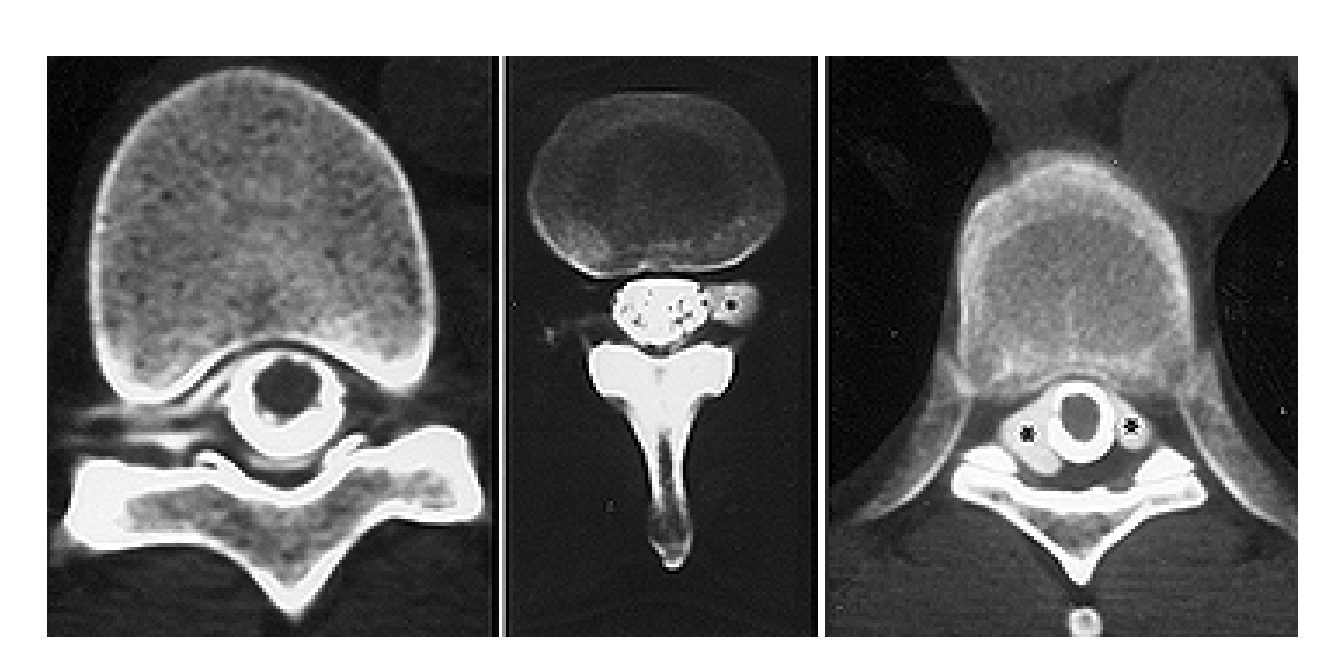

Fig. 7. Postmyelography CT scans demonstrating a focal CSF leak along the right T-12 nerve root in a 24 -year-old man (left); a meningeal diverticulum of the left L-2 nerve root (asterisk) in a 49-year-old woman (center); and bilateral complex meningeal diverticula at the T6-7 level (asterisk) in a 35-year-old woman (right). 


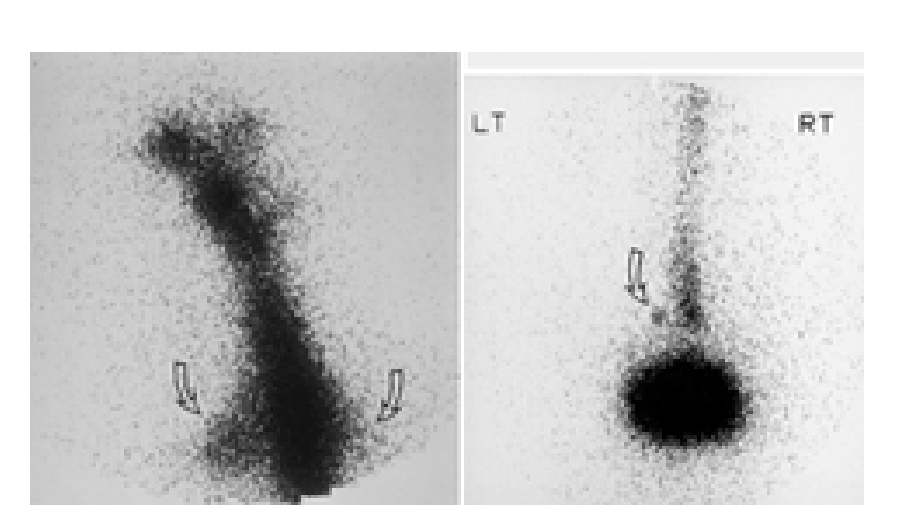

Fig. 8. Radionuclide cisternograms with ${ }^{111}$ Indium-diethylenetraimine pentaacetic acid demonstrating spontaneous CSF leaks at the cervicothoracic junction (curved arrows) in a 51-year-old woman (left) and at the left lumbosacral junction (curved arrow) in a 68-year-old man (right).

diverticula. The CSF leak may appear to be diffuse and the exact site difficult to define, or the leak may be very focal along a single nerve root. The majority of spinal CSF leaks are found at the cervicothoracic junction or in the thoracic spine. Occasionally, multiple simultaneous CSF leaks are demonstrated on myelography at different spinal levels.

Myelography should be performed with thin-slice CT cuts at each spinal level from the foramen magnum to the sacrum, unless a previous imaging study has indicated the approximate level of the leak. If the initial CT myelogram fails to demonstrate a leak, it may be of benefit to have the patient ambulate for some time and then to obtain a delayed CT scan to identify a slow or intermittent spinal CSF leak. Infusion of artificial CSF following the installation of contrast also may improve the detection rate of spinal CSF leaks by increasing intrathecal pressure.

\section{Radionuclide Cisternography}

Radionuclide cisternography with ${ }^{111}$ Indium-diethylenetriamine pentaacetic acid has been used extensively in the evaluation of patients with spontaneous intracranial hypotension (Fig. 8). ${ }^{13,40,50,62,63,70,71,79}$ In most cases, this study will show early accumulation of tracer in the kidneys and bladder, slow ascent along the spinal axis, and less activity than expected over the cerebral convexities. These findings suggest unusually rapid uptake of tracer into the bloodstream through the extensive epidural venous plexus. However, this diagnostic modality identifies the location of the CSF leak in only about two thirds of patients in whom CT myelography has defined spinal CSF leaks. ${ }^{70}$ It is likely that in such cases the CSF leak is below the level of resolution of the radionuclide study. Nevertheless, radionuclide cisternography may be useful to confirm a diagnosis of intracranial hypotension when CT myelography demonstrates normal findings or to aid in the localization of the CSF leak when CT myelography suggests multiple simultaneous spinal CSF leaks.

\section{Spinal MR Imaging}

Spinal MR imaging has played a relatively limited role in the evaluation of patients with spontaneous intracranial

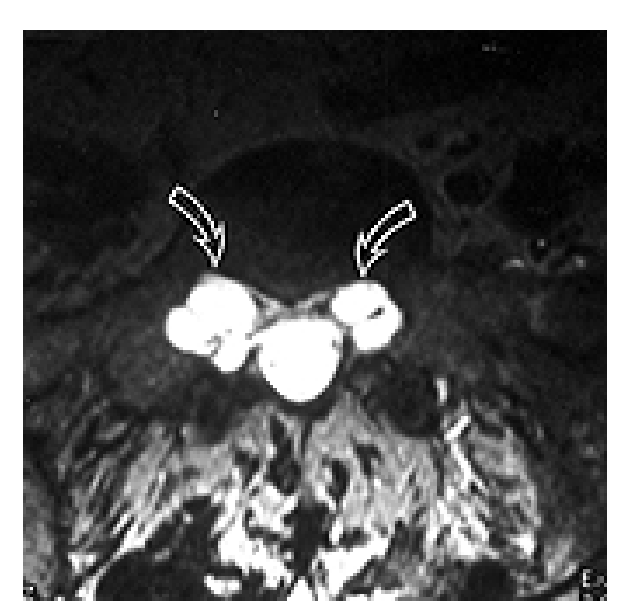

Fig. 9. Axial $\mathrm{T}_{2}$-weighted MR image revealing bilateral complex meningeal diverticula of the S-1 nerve roots (curved arrows) in a 55-year-old woman with Marfan syndrome.

hypotension. ${ }^{43,49,60,62,70}$ Although extrathecal CSF collections and meningeal diverticula are routinely visualized on MR imaging in patients with spontaneous intracranial hypotension (Fig. 9), often MR imaging is not sensitive enough to detect the exact location of the spinal CSF leak. Magnetic resonance myelography is a novel technique ${ }^{31,61}$ that may prove to be valuable in the localization of spinal CSF leaks. ${ }^{41}$ Dilated epidural veins are commonly visualized using MR myelography in patients with spinal CSF leaks, and these veins may mimic an arteriovenous malformation or jugular vein thrombosis. ${ }^{11,43}$

\section{Color Doppler Flow Imaging}

Transorbital color Doppler flow imaging of the superior ophthalmic veins is a recently described method to diagnose intracranial hypotension. ${ }^{10}$ Using this imaging technique, Chen and colleagues ${ }^{10}$ have observed high blood flow velocities in greatly engorged superior ophthalmic veins in all their patients with spontaneous intracranial hypotension. Flow velocities returned to normal after successful treatment of the intracranial hypotension.

\section{TREATMENT OPTIONS}

Fortunately, most cases of spontaneous intracranial hypotension resolve spontaneously or respond well to bed rest and a generous intake of oral fluids. However, the duration of symptoms among patients who seek medical care has ranged from weeks to many years. Medical management of spontaneous intracranial hypotension, which has included the administration of caffeine, glucocorticoid medication, mineralocorticoid agents, and theophylline, ${ }^{30,32,62,70,81}$ usually are of limited benefit.

The injection of autologous blood into the lumbar epidural space, the so-called epidural blood patch, is the initial treatment of choice..$^{5,15,49,70,84}$ Nosik $^{52}$ and Gormley ${ }^{26}$ were the first to report the use of an epidural blood patch for the treatment of intracranial hypotension. They injected only 1 to $3 \mathrm{ml}$ of blood and achieved excellent results. Since then, however, it has been shown that the success rate of the epidural blood patch procedure increases with 
the volume of blood used, from approximately $80 \%$ after injection of 10 to $15 \mathrm{ml}$ of blood to greater than $95 \%$ after injection of $20 \mathrm{ml}$ of blood. ${ }^{12,26}$ Relief of symptoms often is almost instantaneous, and this is likely related to the acute compression of the thecal sac resulting in an increase of CSF pressure. In addition to this acute effect, an epidural blood patch can provide long-term relief by forming a dural tamponade that permanently seals the CSF leak. Nevertheless, in patients with spontaneous intracranial hypotension the benefit of performing the initial epidural blood patch procedure often is only temporary. The epidural blood patch procedure can then be repeated, several times if necessary, and a larger volume of blood, up to $30 \mathrm{ml}$, may be considered for injection. ${ }^{15}$ An important limitation of a large-volume blood patch is the development of back and leg pain. Epidural blood patches have been shown to spread within the epidural space over many spinal levels, ${ }^{80,82}$ and the initial epidural blood patch generally is placed in the lumbar spine regardless of the level of the CSF leak. Therefore, it may not be unreasonable to proceed with this treatment without undertaking any spinal neuroimaging studies to localize the level of the leak. However, if lumbar epidural blood patches fail to provide relief, the next step often is the placement of an epidural blood patch directed at the exact site of the CSF leak, which usually is at least several vertebral levels higher than the lumbar spine..$^{70,71}$ Thoracic or cervical epidural blood patches are associated with a higher risk, ${ }^{14}$ and institutional experience with such directed epidural blood patches may be limited. It has been our experience that the directed epidural blood patch is more successful than the lumbar epidural blood patch, particularly in providing long-term relief.

When the epidural blood patch procedure is ineffective, epidural or intrathecal saline infusion may be considered, ${ }^{13,15,24,49,62,70}$ but such infusions should not be expected to seal the CSF leak. Percutaneous CT-guided placement of fibrin glue into the epidural space may also be an option. This technique has been used successfully in patients who developed postoperative spinal CSF leaks. ${ }^{57}$

Surgical repair of spinal CSF leaks is a safe and generally effective treatment of spontaneous intracranial hypotension in selected patients. ${ }^{34,59,70-72,83}$ Surgery is reserved for patients with persistent symptoms in whom there is evidence of a structural abnormality or focal CSF leak identified on their neuroimaging studies. Different types of leaking spinal meningeal diverticula have been found at surgery, and most of these can be ligated safely. ${ }^{70-72}$ However, in the majority of surgically treated patients a structural abnormality is not demonstrated on their preoperative neuroimaging studies; a focal CSF leak, however, is often observed, and when such a leak is carefully explored, a clear structural cause of the leak is found only rarely. ${ }^{71}$ In these cases, a small dural tear or "blow out" of a small meningeal diverticulum is suspected. Nevertheless, the results of packing of the epidural space and nerve root with fibrin glue at the level of the focal CSF leak have been satisfactory. ${ }^{71}$ I recommend using muscle and gelfoam, and usually apply fibrin glue as well, in such surgically treated cases.

We have observed transient intracranial hypertension associated with papilledema and retinal hemorrhage following successful surgical treatment of a chronic spon- taneous spinal CSF leak. ${ }^{70,71}$ In this case, papilledema resolved spontaneously over a 1-month period. This is an uncommon complication, probably related to the sudden interruption of the abnormal CSF resorption pathway that had been present for many years.

\section{References}

1. Alvarez-Linera $\mathrm{J}$, Escribano $\mathrm{J}$, Benito-Leon $\mathrm{J}$, et al: Pituitary enlargement on MRI in patients with intracranial hypotension. Neurology 54 (Suppl 3):A382, 2000 (Abstract)

2. Anonymous: Case records of the Massachusetts General Hospital. Weekly clinicopathological exercises. Case 2-1998. A 50year-old woman with increasing headache and a left abducentnerve palsy. N Engl J Med 338:180-188, 1998

3. Beck CE, Rizk NW, Kiger LT, et al: Intracranial hypotension presenting with severe encephalopathy. Case report. J Neurosurg 89:470-473, 1998

4. Bell WE, Joynt RJ, Sahs AL: Low spinal fluid pressure syndromes. Neurology 10:512-521, 1960

5. Benzon HT, Nemickas R, Molloy RE, et al: Lumbar and thoracic epidural blood injections to treat spontaneous intracranial hypotension. Anesthesiology 85:920-922, 1996

6. Berlit P, Berg-Dammer E, Kuehne D: Abducens nerve palsy in spontaneous intracranial hypotension. Neurology 44:1552, 1994

7. Billings JJ, Gilford EJ, Henderson JK: The low intracranial pressure syndrome. Proc Aust Assoc Neurol 12:31-34, 1975

8. Blank SC, Shakir RA, Bindoff LA, et al: Spontaneous intracranial hypotension: clinical and magnetic resonance imaging characteristics. Clin Neurol Neurosurg 99:199-220, 1997

9. Bradley KC: Cerebrospinal fluid pressure. J Neurol Neurosurg Psychiatry 33:387-397, 1970

10. Chen CC, Luo CL, Wang SJ, et al: Colour doppler imaging for diagnosis of intracranial hypotension. Lancet 354:826-829, 1999

11. Clarot F, Callonnec F, Douvrin F, et al: Giant cervical epidural veins after lumbar puncture in a case of intracranial hypotension. AJNR 21:787-789, 2000

12. Crawford JS: Epidural blood patch. Anaesthesia 40:381, 1985

13. Davenport RJ, Chataway SJ, Warlow CP: Spontaneous intracranial hypotension from a CSF leak in a patient with Marfan's syndrome. J Neurol Neurosurg Psychiatry 59:516-519, 1995

14. De Rosayro AM, Deck MDF: Commentary. Anesthesiol Rev 14:24, 1987

15. Dillon WP, Fishman RA: Some lessons learned about the diagnosis and treatment of spontaneous intracranial hypotension. AJNR 19:1001-1002, 1998

16. Dodick DW, Bosch EP, Lyons MK: Orthostatic headache syndrome with CSF leak secondary to bony pathology of the cervical spine. Neurology 54 (Suppl 3):A129, 2000 (Abstract)

17. Erkulvrawatr S, El Gammal T, Hawkins J, et al: Intrathoracic meningoceles and neurofibromatosis. Arch Neurol 36: 557-569, 1979

18. Fattori R, Nienaber CA, Descovich B, et al: Importance of dural ectasia in phenotypic assessment of Marfan's syndrome. Lancet 354:910-913, 1999

19. Feindel W, Penfield W, Mcnaughton F: The tentorial nerves and localization of intracranial pain in man. Neurology 10: $555-563,1960$

20. Ferrante E, Savino A, Brioschi A, et al: Transient oculomotor cranial nerves palsy in spontaneous intracranial hypotension. $\mathbf{J}$ Neurosurg Sci 42:177-179, 1998

21. Fishman RA, Dillon WP: Dural enhancement and cerebral displacement secondary to intracranial hypotension. Neurology 43:609-611, 1993

22. Fukutake T, Sakakibara R, Mori M, et al: Chronic intractable headache in a patient with Marfan's syndrome. Headache 37: 291-305, 1997 
23. Garcia-Albea E, Cabrera F, Tejeiro J, et al: Delayed postexertional headache, intracranial hypotension and racket sports. J Neurol Neurosurg Psychiatry 55:975, 1992

24. Gibson BE, Wedel DJ, Faust RJ, et al: Continuous epidural saline infusion for the treatment of low CSF pressure headaches. Anesthesiology 68:789-791, 1988

25. Good DC, Ghobrial M: Pathologic changes associated with intracranial hypotension and meningeal enhancement on MRI. Neurology 43:2698-2700, 1993

26. Gormley JB: Treatment of postspinal headache. Anesthesiology 21:565-566, 1960

27. Headache Classification Committee of the International Headache Society: Classification and diagnostic criteria for headache disorders, cranial neuralgias and facial pain. Cephalalgia 8 (Suppl 7): 1-96, 1988

28. Hochman MS, Naidich TP, Kobetz SA, et al: Spontaneous intracranial hypotension with pachymeningeal enhancement on MRI. Neurology 42:1628-1630, 1992

29. Horton JC, Fishman RA: Neurovisual findings in the syndrome of spontaneous intracranial hypotension from dural cerebrospinal fluid leak. Ophthalmology 101:244-251, 1994

30. Huber M: [Spontaneous hypoliquorrhea. Report of 7 personal observations.] Schweiz Arch Neurol Neurochir Psychiatr 106:9-23, 1970 (Ger)

31. Jara H, Barish MA, Yucel EK, et al: MR hydrography: theory and practice of static fluid imaging. AJR 170:873-882, 1998

32. Kasner SE, Rosenfeld J, Farber RE: Spontaneous intracranial hypotension: headache with a reversible Arnold-Chiari malformation. Headache 35:557-559, 1995

33. Kimmel JL: Innervation of spinal dura mater and dura mater of the posterior cranial fossa. Neurology 11:800-809, 1961

34. Krämer G, Hopf HC, Eissner D: CSF hyperabsorption: a cause of spontaneous low CSF pressure headache. Neurology 37: 238, 1987 (Abstract)

35. Labadie HL, van Antwerp J, Bamford CR: Abnormal lumbar isotope cisternography in an unusual case of spontaneous hypoliquorrheic headache. Neurology 26:135-139, 1976

36. Lasater GM: Primary intracranial hypotension. The low spinal fluid pressure syndrome. Headache 10:63-66, 1970

37. Lehman RAW, Stears JC, Wesenberg RL, et al: Familial osteosclerosis with abnormalities of the nervous system and meninges. J Pediatr 90:49-54, 1977

38. Lindquist T, Moberg E: Spontaneous hypoliquorrea. Acta Med Scand 132:556-561, 1949

39. Lyons MK, Meyer FB: Cerebrospinal fluid physiology and the management of increased intracranial pressure. Mayo Clin Proc 65:684-707, 1990

40. Marcelis J, Silberstein SD: Spontaneous low cerebrospinal fluid pressure headache. Headache 30:192-196, 1990

41. Matsumura A, Anno I, Kimura H, et al: Diagnosis of spontaneous intracranial hypotension by using magnetic resonance myelography. Case report. J Neurosurg 92:873-876, 2000

42. Miles J, Pennybacker J, Sheldon P: Intrathoracic meningocele: its development and association with neurofibromatosis. J Neurol Neurosurg Psychiatry 32:99-110, 1969

43. Miyazawa K, Shiga Y, Endoh M, et al: The diagnostic efficacy of magnetic resonance imaging of the spinal cord in spontaneous intracranial hypotension. Neurology 54 (Suppl 3):A128, 2000 (Abstract)

44. Moayeri NN, Henson JW, Schaefer PW, et al: Spinal dural enhancement on magnetic resonance imaging associated with spontaneous intracranial hypotension. Report of three cases and review of the literature. J Neurosurg 88:912-918, 1998

45. Mokri B, Atkinson JLD: False pituitary tumor in spontaneous cerebrospinal fluid leak. Ann Neurol 46:475, 1999 (Abstract)

46. Mokri B, Atkinson JLD, Dodick DW, et al: Absent pachymeningeal gadolinium enhancement on cranial MRI despite symptomatic CSF leak. Neurology 53:402-404, 1999

47. Mokri B, Krueger BR, Miller GM, et al: Meningeal gadolini- um enhancement in low pressure headaches. Ann Neurol 30: 294-295, 1991 (Abstract)

48. Mokri B, Parisi JE, Scheithauer BW, et al: Meningeal biopsy in intracranial hypotension: meningeal enhancement on MRI. Neurology 45:1801-1807, 1995

49. Mokri B, Piepgras DG, Miller GM: Syndrome of orthostatic headaches and diffuse pachymeningeal gadolinium enhancement. Mayo Clin Proc 72:400-413, 1997

50. Molins A, Alvarez J, Sumalla J, et al: Cisternographic pattern of spontaneous liquoral hypotension. Cephalalgia 10:59-65, 1990

51. Nakajima H, Sakai T, Aoki N, et al: Bilateral chronic subdural hematomas associated with intracranial hypotension-case report. Neurol Med Chir 36:647-649, 1996

52. Nosik WA: Intracranial hypotension secondary to lumbar nerve sleeve tear. JAMA 157:1110-1111, 1955

53. O'Carroll CP, Brant-Zawadzki M: The syndrome of spontaneous intracranial hypotension. Cephalalgia 19:80-87, 1999

54. Page F: Intracranial hypotension. Lancet 1:1-5, 1953

55. Pakiam AS, Lee C, Lang AE: Intracranial hypotension with parkinsonism, ataxia, and bulbar weakness. Arch Neurol 56: 869-872, 1999

56. Pannullo SC, Reich JB, Krol G, et al: MRI changes in intracranial hypotension. Neurology 43:919-926, 1993

57. Patel MR, Louie W, Rachlin J: Postoperative cerebrospinal fluid leaks of the lumbosacral spine: management with percutaneous fibrin glue. AJNR 17:495-500, 1996

58. Philip N, Andrac L, Moncla A: Multiple lateral meningoceles, distinctive facies and skeletal anomalies: a new case of Lehman syndrome. Clin Dysmorphol 4:347-351, 1995

59. Pleasure SJ, Abosch A, Friedman J, et al: Spontaneous intracranial hypotension resulting in stupor caused by diencephalic compression. Neurology 50:1854-1857, 1998

60. Rabin B, Roychowdhury J, Meyer JR, et al: Spontaneous intracranial hypotension: spinal MR findings. AJNR 19: 1034-1039, 1998

61. Ramsbacher J, Schilling AM, Wolf KJ, et al: Magnetic resonance myelography (MRM) as a spinal examination technique. Acta Neurochir 139:1080-1084, 1997

62. Rando TA, Fishman RA: Spontaneous intracranial hypotension: report of two cases and review of the literature. Neurology 42: 481-487, 1992

63. Renowden SA, Gregory R, Hyman N, et al: Spontaneous intracranial hypotension. J Neurol Neurosurg Psychiatry 59: 511-515, 1995

64. Sable SG, Ramadan NM: Meningeal enhancement and low CSF pressure headache: an MRI study. Cephalalgia 11: 275-276, 1991

65. Sato Y, Honda Y, Maruoka H, et al: Recurrence of spontaneous intracranial hypotension with subdural hematomas. Cephalalgia 17:42-45, 1997

66. Sato Y, Honda Y, Maruoka H, et al: Subdural hematoma following disappearance of orthostatic headache and pressure normalization in two patients with spontaneous intracranial hypotension. Cephalalgia 18:60-63, 1998

67. Schaltenbrand G: Neuere Anschauungen zur Pathophysiologie der Liquorzirkulation. Zentralbl Neurochir 3:290-300, 1938

68. Schaltenbrand G: Normal and pathological physiology of the cerebrospinal fluid circulation. Lancet 1:805-808, 1953

69. Schievink WI, Ebersold MJ, Atkinson JLD: Roller-coaster headache due to spinal cerebrospinal fluid leak. Lancet 347: 1409, 1996

70. Schievink WI, Meyer FB, Atkinson JLD, et al: Spontaneous spinal cerebrospinal fluid leaks and intracranial hypotension. J Neurosurg 84:598-605, 1996

71. Schievink WI, Morreale VM, Atkinson JLD, et al: Surgical treatment of spontaneous spinal cerebrospinal fluid leaks. J Neurosurg 88:243-246, 1998

72. Schievink WI, Reimer R, Folger WN: Surgical treatment of 


\section{Spontaneous spinal CSF leaks}

spontaneous intracranial hypotension associated with a spinal arachnoid diverticulum. Case report. J Neurosurg 80:736-739, 1994

73. Schievink WI, Schrijver I, Meyer FB, et al: A syndrome of spontaneous spinal cerebrospinal fluid leaks and skeletal features of Marfan syndrome. Ann Neurol 44:458, 1998

74. Schievink WI, Smith KA: Nonpositional headache caused by spontaneous intracranial hypotension. Neurology 51: 1768-1769, 1998

75. Schievink WI, Torres VE: Spinal meningeal diverticula in autosomal dominant polycystic kidney disease. Lancet 349: 1223-1224, 1997

76. Schievink WI, Tourje J: Intracranial hypotension without meningeal enhancement on magnetic resonance imaging. Case report. J Neurosurg 92:475-477, 2000

77. Shevell MI, Evans BK: The "Schaltenbrand experiment," Wurzburg, 1940: scientific, historical, and ethical perspectives. Neurology 44:350-356, 1994

78. Shimazu N, Oba H, Aoki S, et al: [Pituitary enlargement in spontaneous intracranial hypotension on MRI.] Nippon Igaku Hoshasen Gakkai Zasshi 58:349-352, 1998 (Jpn)

79. Spelle L, Boulin A, Pierot L, et al: Spontaneous intracranial hypotension: MRI and radionuclide cisternography findings. J Neurol Neurosurg Psychiatry 62:291-302, 1997
80. Szeinfeld M, Ihmeidan IH, Moser MML, et al: Epidural blood patch: evaluation of the volume and spread of blood injected into the epidural space. Anesthesiology 64:820-822, 1986

81. Teng P, Papatheodorou C: Primary cerebrospinal fluid hypotension. Bull LA Neurol Soc 33:121-128, 1968

82. Vakharia SB, Thomas PS, Rosenbaum AE, et al: Magnetic resonance imaging of cerebrospinal fluid leak and tamponade effect of blood patch in post-dural puncture headache. Anesth Analg 84:585-590, 1997

83. Vishteh AG, Schievink WI, Baskin JJ, et al: Cervical bone spur presenting with spontaneous intracranial hypotension. Case report. J Neurosurg 89:483-484, 1998

84. Weitz SR, Drasner K: Spontaneous intracranial hypotension: a series. Anesthesiology 85:923-925, 1996

85. Yamamoto M, Suehiro T, Nakata H: Primary low cerebrospinal fluid pressure sydrome associated with galactorrhea. Intern Med 32:228-231, 1993

Manuscript received May 15, 2000.

Accepted in final form June 8, 2000.

Address reprint requests to: Wouter I. Schievink, M.D., Maxine Dunitz Neurosurgical Institute, Cedars-Sinai Medical Center, 8631 West Third Street, Suite 800E, Los Angeles, California 90048. email: schievinkw@cshs.org. 